\title{
Effect on Private College Student's Morality Caused by Network Media
}

\author{
Yuntao Liu and Chunwei Wang \\ Xijing University, Shaanxi Xian 71023 \\ 75700789@qq.com
}

Keywords: Network media; Private Colleges; Moral cultivation; Effect

\begin{abstract}
Network media is influencing private college students' moral cognition, behavior and psychology from various perspectives. This paper is going to analyze the effect on their morality caused by network media from both positive and negative ways based on dialectical thinking, hoping to help private colleges make good preparations for moral cultivation in the situation that private colleges are growing vigorously.

Network, as an important media and method in the current era, is changing people's production, living styles as well as ideology and ideas. Moral cultivation for college students is a process of learning by doing, which does not only require theoretical learning but also practice. Private colleges, as cultural education places, provide a good environment for moral cultivation. Therefore, moral cultivation education of college students should be an important part of education. However, with the rapid development of network media driven by science and technology, moral education of private college students in the virtual world is facing unprecedented chances and opportunities.
\end{abstract}

\section{Overview of Network Media}

Network media, taking network as the carrier, releases information and provides a place to change ideas. With furthermore development of science and technology, the media also goes through diversified development, which has become an important carrier and tool for people to receive education, carry out interpersonal communication etc, bringing about profound reform and effect on economy and people's life.

Network media emerges along with the advancement of technology as well as society, and, the improvement of human civilization requires higher demand on information need and media. The rapid development of network technology provides powerful support for this need and broad space for the development of media. As the social main body, human beings are experiencing material and spiritual development, asking higher demand on communication and its methods, which trigger the rapid development of network media.

\section{Bad Effect on Private College Students' Morality Caused by Network Media}

The function of network media is various, which can be considered as a double sword. On the one hand, it can broaden the range to develop moral cultivation and on the other hand get rid of interference because of miscellaneous information [3]. Internet network is in time, massive, interactive and facing various media, which can bring about both positive and passive effect. To dialectically judge and analyze the effect on private college students' morality caused by network media is the main idea of this paper.

College students in adolescence do not have mature morality and their characteristics can be shaped. In a diverse and complicated network environment, the psychological structure of college students' morality is shocked. The direction system, motivation system, and controlling system of moral cultivation are all facing new challenges. They will reconstruct their morality while playing games and chatting online. Because of physical maturity, curiosity and strong desire, they will demonstrate diverse needs. Based on this, they will embrace the positive stuff online but will also purse wrong, fake, pornographic and violent culture. Because of limited cognition and immature morality, the network media will bring about negative effect on their morality cultivation. 
To begin with, they lack morality, showing in indifference, uncertainty and immoral activities. We can see their indifference based on the change of honest. The fraud, and fake information have triggered less communication, security and trust lost. So, students will change their cognition and abandon original honesty beliefs, believing that there is no trust among people. Comparing to moral sharpening, this kind of behavior is real cognition which will become moral belief. College students have access to express their feelings online and they will get spiritual partners online but get more and more indifferent in real life. As time passes by, they will feel unstable and lonely. In addition, the declining of moral standards and indifferent attitude will cause bad effect on college students' morality. As a result, they may conduct faking, invading other people's privacy, cursing and immoral relation.

Secondly, moral sharpening. Moral sharpening refers to a moral phenomenon that the main subjects get more defined moral principles, showing in the following aspects: firstly, words are not matched by deeds, which is the most common phenomenon. Secondly, inconsistency or duplicity. Moral subjects are affected by benefits and environment, they sometimes obey moral rules while sometime get rid of it. Thirdly, their behaviors will suddenly change. In reality, we may face a situation that a person used to be very nice, becomes a criminal in one night. Unhealthy network culture makes students cognition fuzzy and become indifferent, thus we can understand that they don't have stable moral standards.

\section{Prospects for Effect on Private College Students' Morality Caused by Network Media}

The big data era pushes the vigorous development of network media. The internet, as the platform for information, carries a bunch of information beyond imagination, which overcomes asymmetric information but meanwhile brings about information redundancy. Private college students are considered as the frontier connecting with the internet, we have to on the one hand focus on their life view, world view and value education to construct correct values and avoid unhealthy thinking; and on the other hand cooperate with relevant offices to make healthy network environment to construct health and positive moral environment. Network media, as a new one, has more advantages comparing to traditional ones, so we should draw on the advantages and avoid disadvantages to guide and implement good moral education.

Strengthen Network Legislation and Perfect Supervisory Control. Since 1990s, our government has formulated laws and regulations like Regulations of the People's Republic of China for Safety Protection of Computer Information System, and Measures for Security Protection Administration of the International Networking of Computer Information Networks to regulate and manage safety problems. The complicated network environment as well as the rapid development of internet brings us convenience but also a series of unprecedented problems and the hysteresis of law will definitely cause lax regulation and supervision. Therefore, the government should cooperate with relevant information technology department to implement allied special legislation and meanwhile increase punishment; they should supervise on various websites and prohibit violent pornographic and other harmful information, modify unhealthy information so as to cultivate a good environment. What's more, the government should also strengthen the supervision on network to timely filter harmful information; furthermore, take advantage of the administration function, invite people from colleges and website to give lectures to discuss measures to purify the network environment. Based on various measures should we construct a good moral education environment.

Website Founder Should Firmly Establish Responsibility and Strictly Check Information. There is a serve competition among network media and their survival as well as development requires attention from network citizens. However, as a communication media, they should perfectly act the role of gatekeeper to coordinate good economic benefits and social benefits, and meanwhile take the responsibility of media and society. Website founder should also adhere to the principle of promoting the main theme and positive attitudes, merits of traditional Chinese culture and vigorously develop patriotism and collectivism, strictly against reactionary, superstitious, violent, obscene actions to take core value to socialism to lead the value cultivation. [6] In addition, 
they should establish hierarchical website to make college students have limited access so as to avoid unhealthy websites.

\section{College Should Play Well the Leading Role of College Students Morality Cultivation}

1. Fully play the role of network media to well implement ideological-political subject education

Ideological-political subject class in college is the main channel for them to receive moral education which is also an important education method, so we should fully play its role. To be concrete, we should firstly strengthen the teaching team construction to cultivate a high quality teaching team proficient in modern network technology. These teachers should understand students' learning motivation and ideological thoughts so as to analyze their morality based on network technology. Secondly, take advantage of network media to enrich the teaching content, update teaching methods. For example, they can make lively teaching case to make recreational education so as to help students understand the theory and improve teaching effect.

2. Carry out various moral education activities to lead college network culture

We can take advantage of the education advantage of schools to carry out theme activities named 'How to cultivate good morality under the influence of network media' based on lectures, symposium, discussion, debate, speech etc; what's more, a Mental Consultation Tutor Station can be set up to correct students; furthermore, we can also encourage students to participate in volunteer activities such as holding Volunteer Activities for the Country People to let students go into the life of society, country to experience moral practice. Based on the above, we should avoid scripted education and create a equal and harmonious environment to let students participate more in various campus activities to combine creation and education, which should be attractive and can strengthen college students' values and form correct moral ideas.

3. Fully play the positive role of school website and micro media

To study on the morality cultivation under the influence of network media can also help to play the role of the media itself. Concerning schools, they can take advantage of their websites to make students study online and carry out research so that we can understand students' appetites to establish websites with better quality and more attractive stuff. What's more, we can especially establish patriotic education based on technology; through mailbox, we can also create a channel for students and teachers to communicate smoothly; what's more, the moral cultivation makes college students create the sense of master. What's more, we should also keep pace with the micro time to fully play the role of micro media. For example, we can establish official we chat and weibo to timely carry out moral education for students to achieve better results.

\section{College Students Should Pay Attention to Individual Morality Cultivation}

The morality cultivation process is affected by both internal and external causes so students should play their autonomy, initiative and creativity as the internal cause and main body. College students are successors of the future, so they should improve their cognition of moral cultivation to establish correct world views, life views, values and political beliefs. In addition, they should possess good morality to positively do discipline and make it clear of their responsibility as well as negative and positive effect caused by the network media. They should have a strong will to absorb good sides and strictly avoid bad sides, take the initiative to participate various practices to build good morality. At the same time, as the inheritor of emerging technology, students should highlight their main body to promote good stuff and correct values, adjust criteria to adjust social relation and construct environment adapted to the modern civilization.

\section{Foundation Item}

Research findings of Moral cultivation education for private college students of Xijing College scientific researching fund projects, project number (XJ130139) 


\section{References}

[1] Wang Zhilin. Brief analysis on the effect on ideological and political work caused by network media [J]. Chinese Newspaper Industry, 2011, 12 (II): 78-80.

[2] Ban Rongding. The Path of Great Learning: theory and practice of college students morality cultivation [M]. Beijing: the People are Publishing House, 2009.

[3] Xu Honglei. Study on the path to cultivate college students' morality [D] Beijing: China University of Geosciences, 2010

[4] Wei Zhenbo, Li Xinjin. Effect and policy of network culture for college students morality [J]. China metallurgical education, 2010, 06:72-74.

[5] Zhou Lanfeng. Analyze on the effect on college students morality caused by mass media: Take colleges in Fujian as examples. [J]. Journal of Chuzhou University, 2011, (6)

[6] [2014-07-30].http://www.xchen.com.cn/baogao/diaochabaogao/8668.html.

[7] Report on College students' morality showing online [EB/OL]. ( 2014-07-30 ) [2014-07-30].http://www.xchen.com.cn/baogao/diaochabaogao/8668.html.

[8] Long Yanping etc. Discuss on the effect on college students' morality education caused by new media [J]. Journal of Longdong College, 2014 (1)

[9] Tao Dan, Zhang Haoda. New media and Internet Communication. Beijing: Science Press, 2001

[10]Jing Dong, Su Baohua. New view on new media. The press, 2008(3): 58

[11]Zhang Zaixing etc. Research on network ideological and political education. Beijing: Economic Science Press, 2009 